\title{
Activity and Calcium-Dependent Mechanisms Maintain Reliable Interneuron Synaptic Transmission in a Rhythmic Neural Network
}

\author{
David Parker \\ Nobel Institute for Neurophysiology, Department of Neuroscience, Karolinska Institute, S-17177, Stockholm, Sweden
}

Inputs from glutamatergic excitatory interneurons (EIN) to motor neurons in the lamprey spinal cord locomotor network exhibit activity-dependent depression during spike trains. The mechanism underlying this depression has been examined here, and its relevance to transmitter release during rhythmic activity has been investigated.

The depression of EIN inputs was greater after larger initial EPSPs and reduced in low-calcium Ringer's solution, effects that are consistent with depression caused by depletion of releasable transmitter stores. However, the depression was greater at lower stimulation frequencies and could be reversed by increasing the stimulation frequency. In addition, highcalcium Ringer's solution and the slow intracellular calcium chelator EGTA-AM, which both failed to affect the amplitude of low frequency-evoked EPSPs, reduced and increased the depression, respectively. These results are inconsistent with a simple depletion mechanism but suggest that ongoing activity and calcium-dependent mechanisms oppose depletion.

Short-term activity-dependent synaptic plasticity could contribute to the cycle to cycle patterning of rhythmic network activity (Getting, 1989; Parker and Grillner, 1999). Rhythmic networks can be active over prolonged time periods. Thus, mechanisms must exist to ensure that synaptic transmission, and where appropriate its plasticity, occurs consistently over a range of burst frequencies and patterns, if stable, prolonged activity is to be generated.

Activity-dependent synaptic depression has been suggested to contribute to the patterning of network activity. For example, it may underlie the timing of spontaneous episodes of rhythmic activity in the embryonic chick spinal cord (Fedirchuk et al., 1999) and epileptiform activity in the hippocampus (Staley et al., 1998), and computer simulations suggest that short-term depression may contribute to cyclical activity in cultured spinal neurons (Senn et al., 1996). Depression of graded synaptic transmission also occurs in response to physiologically relevant stimulation in the stomatogastric system (Manor et al., 1997). I have recently examined the activity-dependent plasticity of synaptic transmission from excitatory and inhibitory interneurons in the lamprey spinal cord locomotor network (Parker and Grillner 1999; my

Received Oct. 13, 1999; revised Nov. 29, 1999; accepted Dec. 23, 1999.

This work was supported by grants from the Wellcome Trust, Swedish Medical Research Council (12589), Åke Wibergs Foundation, and the Swedish Brain Foundation. I thank Patriq Fagerstedt, Oleg Shupliakov, Sten Grillner, and Erik Svensson for discussions and comments on this manuscript.

Correspondence should be addressed to D. Parker, Nobel Institute for Neurophysiology, Department of Neuroscience, Karolinska Institute, S 17177, Stockholm, Sweden. E-mail: david.parker@neuro.ki.se.

Copyright (C) 2000 Society for Neuroscience $0270-6474 / 00 / 201754-13 \$ 15.00 / 0$
The network relevance of this mechanism was examined using physiologically relevant bursts to simulate EIN spiking during rhythmic activity. Although considerably more EPSPS were evoked than during spike trains, burst-evoked EPSPs did not depress. However, single EPSPs evoked at the interburst interval depressed, and burst transmission was disrupted by EGTA-AM, again suggesting the involvement of activity and calcium-dependent mechanisms. By responding to the calcium changes evoked by increased interneuron activity, this mechanism can monitor transmitter requirements caused by EIN spiking, allowing reliable transmission across different patterns of network activity. However, not all types of spinal interneurons exhibit reliable burst transmission, suggesting specificity of this mechanism to a subset of neurons.

Key words: synaptic plasticity; depression; lamprey; spinal cord; neural network; transmitter release

unpublished observations). Inputs from excitatory glutamatergic interneurons (EIN), which provide excitatory drive at the segmental network level (Buchanan et al., 1989) to motor neurons exhibit short-term depression during spike trains at frequencies of 5-20 Hz (Parker and Grillner, 1999). In this study, the mechanism underlying the depression of EIN synaptic transmission, and its network relevance, has been examined. The plasticity of inputs from glycinergic crossed caudal interneurons that has also been examined previously (Parker and Grillner, 1999) has not been analyzed further here, because the role of these interneurons in the segmental network, which currently forms the focus of this work, is uncertain (Buchanan, 1999; Buchanan and Kasicki, 1999; my unpublished observations).

Several mechanisms can contribute to activity-dependent synaptic depression. Presynaptic mechanisms include the modulation of action potential conductances (Klein, 1995; Parker, 1995), autoreceptor-mediated inhibition of transmitter release (Forsythe and Clements, 1990), depletion of the releasable vesicle pool (Liley and North, 1953; Kusano and Landau, 1975), modulation of calcium entry (Man-Song and Zoran, 1989; Forsythe et al., 1998), or modulation of the transmitter release machinery (Dale and Kandel, 1990; Shupliakov et al., 1995; Hsu et al., 1996; Miller, 1998). Postsynaptic mechanisms, such as receptor desensitization (Trussell et al., 1993; Otis et al., 1996; Jones and Westbrook, 1996) or voltage-activated dendritic conductances (Johnston et al., 1996; Cash and Yuste, 1999; Cook and Johnston, 1999) could also influence the amplitude of synaptic inputs.

The results of this study suggest that the depression of EIN inputs is attributable to the gradual depletion of the releasable 
vesicle pool, which is opposed by an ongoing activity and calciumdependent mechanism. This mechanism helps to maintain transmitter release during physiologically relevant spike bursts by monitoring the increases in intracellular calcium levels resulting from synaptic activity. It can thus adapt transmitter release to changes in interneuron spiking underlying different patterns of network activity.

\section{MATERIALS AND METHODS}

Adult male and female lampreys (Lampetra fluviatilis) were anesthetized with tricaine methane sulfonate (MS-222; Sandoz, Basel, Switzerland), and the spinal cord and notochord were removed. Pieces of the rostral region of the spinal cord were isolated from the notochord, and the connective tissue and meninx primitiva were removed from the dorsal and ventral surfaces. The spinal cord was then placed ventral side up in a Sylgard (Sikema, Stockholm, Sweden)-lined chamber. A plastic net was placed over the cord and pinned into the Sylgard to keep the cord stable. The cord was superfused with Ringer's solution containing (in mM): 138 $\mathrm{NaCl}, 2.1 \mathrm{KCl}, 1.8 \mathrm{CaCl}_{2}, 1.2 \mathrm{MgCl}_{2}, 4$ glucose, $2 \mathrm{HEPES}, 0.5$ L-glutamine, which was bubbled with $\mathrm{O}_{2}$ with the $\mathrm{pH}$ adjusted to 7.4. Calcium levels in the Ringer's solution were reduced to $50 \%$ in lowcalcium Ringer's solution and increased to $200 \%$ in high-calcium Ringer's solution, the concentration of $\mathrm{NaCl}$ being adjusted accordingly to maintain osmolarity. The experimental chamber was kept at a temperature of $8-12^{\circ} \mathrm{C}$

Paired intracellular recordings were made from the somata or axons of EINs (Buchanan et al., 1989) and the somata of ipsilateral motor neurons in the gray matter region of the spinal cord, using thin or thick-walled glass micropipettes filled with $4 \mathrm{M}$ potassium acetate and $0.1 \mathrm{M}$ potassium chloride (resistances of $\sim 40-100 \mathrm{M} \Omega$ ). Motor neurons were identified by recording orthodromic spikes in the adjacent ventral root after current injection into their somata. EINs were identified by their ability to elicit monosynaptic EPSPs in motor neurons. Monosynaptic potentials were identified by their short, constant latency after presynaptic stimulation at frequencies of $10-20 \mathrm{~Hz}$. EINs were impaled in the same or up to two segments rostral to the postsynaptic motor neuron, the location of the EIN not influencing the plasticity of their inputs (my unpublished observation). Strychnine ( $5 \mu \mathrm{M})$ was usually added to block polysynaptic glycinergic inhibitory inputs that can be elicited during spike trains (my unpublished observation). Postsynaptic motor neurons with a high level of spontaneous EPSPs were not used because this activity made measurement of the evoked EPSP difficult.

Spikes were evoked in EINs either by injecting $1 \mathrm{msec}$ depolarizing current pulses of $10-60 \mathrm{nA}$, or, where possible, on rebound from hyperpolarizing current pulses $(2-5 \mathrm{msec}, 10-60 \mathrm{nA})$. A previous study showed that EINs often failed to spike during glutamate-evoked network activity, although in some cases bursts of several spikes occurred (Buchanan et al., 1989, their Fig. 8; my unpublished observations). The EINs are small and thus easily damaged, making it difficult to obtain direct information on their spiking during network activity and leaving uncertainty as to whether the recorded activity mirrors that occurring physiologically. Because of this uncertainty, it seemed reasonable to base the present analysis on the assumption that EINs behave in the same way as other excitatory and inhibitory network interneurons, which fire up to five spikes at frequencies of $5-30 \mathrm{~Hz}$ (Buchanan and Cohen, 1982; Buchanan and Kasicki, 1995), an assumption that has also been used in computer simulations of network activity (Hellgren et al., 1992). The upper frequency usually used here was $20 \mathrm{~Hz}$ because this limited EPSP summation and thus facilitated the measurement of individual EPSP amplitudes. Where responses to spike trains were examined, 20 or 100 spikes were evoked at 5-20 Hz (Parker and Grillner, 1999). Test pulses were given at the end of the 20 spike trains to measure the recovery from depression (Parker and Grillner, 1999). Graphs plot stimulus number, and thus the test pulses are EPSPs numbered 21-25, corresponding to latencies of $200 \mathrm{msec}, 700 \mathrm{msec}, 1.2 \mathrm{sec}, 2 \mathrm{sec}$, and $3 \mathrm{sec}$ after the end of the train, respectively. Spike trains were evoked at 1 min intervals. The stimulation frequency during the train was varied to prevent possible order effects on the plasticity. The initial EPSP in the train was used to provide a measure of the amplitude of low frequency-evoked EPSPs.

An Axoclamp 2A amplifier (Axon Instruments, Foster City, CA) was used for amplification and in discontinuous current-clamp mode for current injection. Unless stated otherwise, the membrane potential of the postsynaptic cell was kept constant by injecting depolarizing or hyperpolarizing current. Axon Instruments software (pClamp6) was used for writing and triggering stimulation protocols and data acquisition and analysis, using a 486 personal computer equipped with an analog-todigital interface (Digidata 1200; Axon Instruments).

EPSP amplitudes were measured as the peak amplitude above the baseline immediately preceding the spike. EIN EPSPs only rarely have an electrical component (Buchanan et al., 1989), and thus this did not complicate the analysis of the chemical EPSP. Unless stated otherwise, the significance of the plasticity during spike trains was examined by dividing the train into three regions, the initial region covering the second to fifth EPSPs $\left(\operatorname{Train}_{2-5}\right)$, the mid region covering the sixth to tenth EPSPs ( $\left.\operatorname{Train}_{6-10}\right)$, and the final region from the eleventh to twentieth EPSPs (Train Th-20 $_{11}$ ). The EPSPs during each part of the train were averaged, and the average values were compared to the amplitude of the initial EPSP. In burst stimulation experiments, the summed input during each burst was measured by averaging the EPSPs. In some experiments, the EIN axonal action potential spike amplitude (the peak potential reached above the prespike baseline), spike duration (at halfheight), and afterhyperpolarization (AHP) amplitude (the peak hyperpolarized membrane potential reached after the spike) were measured.

All drugs were applied by bath application. In the text, $n$ refers to the number of pairs examined. Several EIN to motor neuron pairs were examined in each piece of spinal cord. However, only one experiment was performed in each piece of spinal cord when modified Ringer's solution or drugs were used, and no more than two examples of any type of experiment was obtained from a single animal. Unless stated otherwise, EPSP amplitudes and spike properties have been normalized on the graphs. Values in Results are mean \pm SEM. Unless stated otherwise, statistical significance was examined using two-tailed paired or independent $t$ tests. All values, whether an effect was seen or not, were included in the statistical analysis.

\section{RESULTS}

The amplitude of glutamatergic EPSPs evoked in motor neurons by EINs exhibits short-term activity-dependent depression during trains of 20 spikes at frequencies of $5-20 \mathrm{~Hz}$ (Parker and Grillner, 1999). This depression is not associated with any significant changes in the EPSP width, rise, or decay time $(p>0.1, n=10$; data not shown). The depression of the EPSP amplitude occurs between the fifth and tenth spikes in the train, and in some cases can develop from an initial facilitation at $20 \mathrm{~Hz}$. The depression is greater at lower stimulation frequencies, the order of the depression being $5 \mathrm{~Hz} \geq 10 \mathrm{~Hz}>20 \mathrm{~Hz}$ (Fig. 1). By itself, this frequency dependence suggests that the depression is not simply caused by depletion, because depletion should increase with increasing stimulation frequencies. The initial analysis of the mechanisms underlying the depression examined the potential role of depletion in detail.

\section{Examination of the effect of stimulation duration and frequency on depression}

The depression of EIN inputs at $5-20 \mathrm{~Hz}$ appears to reach its maximum level by the tenth spike in the train (Parker and Grillner, 1999). However, with the trains of 20 spikes used previously, it was not possible to determine with certainty if the depression reaches a plateau level or if it increases throughout the spike train, as would be expected if the depression was caused by depletion. Trains of 100 spikes were thus used to determine if the depression plateaued. As in the previous study, the depression was greater with lower stimulation frequencies $(5 \mathrm{~Hz} \geq 10 \mathrm{~Hz}>$ $20 \mathrm{~Hz}$; Parker and Grillner, 1999), and at each frequency, a significant level of depression (50-70\% of control) was reached by the tenth spike ( $p<0.05$; Fig. $1 A-D)$, the depression not increasing significantly from this level during the remainder of the spike train $(n=5$ of $5 ; p>0.1)$. The fact that the depression reached 
A

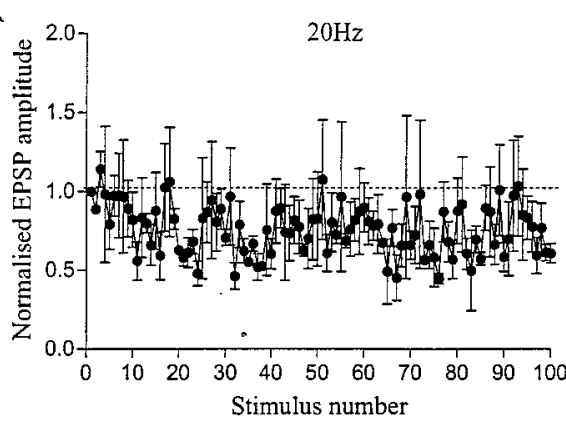

C

Figure 1. The depression of EIN inputs reaches a plateau level during spike trains. Trains of 100 spikes were delivered at $20(A)$, $10(B)$, and $5(C) \mathrm{Hz}$. At each frequency $(n=$ $5)$, the depression reached a plateau level by approximately the tenth spike in the train. $D$, Traces of EIN inputs evoked at frequencies of $5-20 \mathrm{~Hz}$, showing the initial EPSP in the train and average EPSP amplitudes measured over EPSPs 15-20, and 95-100, showing the stability of the depression once it had developed. Note that the depression is greater at lower stimulation frequencies. In all figures, the EIN input is onto a postsynaptic motor neuron. $E$, Increasing the stimulus frequency reverses the depression of EIN inputs. Alternating trains of 20 spikes at 5 and $20 \mathrm{~Hz}$ were given to give a total number of 1000 EPSPs. During each $5 \mathrm{~Hz}$ burst, depression developed to the $5 \mathrm{~Hz}$ plateau level, but was reversed when $20 \mathrm{~Hz}$ stimulation began. The graph shows the activity over the 500th to 1000th EPSPs in a single experiment. Traces are average EPSP amplitudes from the region of the graph below the trace. The bars indicate the duration of 5 (bottom bars) and $20 \mathrm{~Hz}$ stimulation (top bars).
B

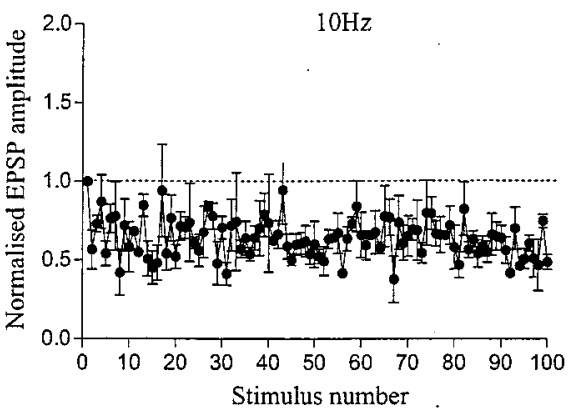

D

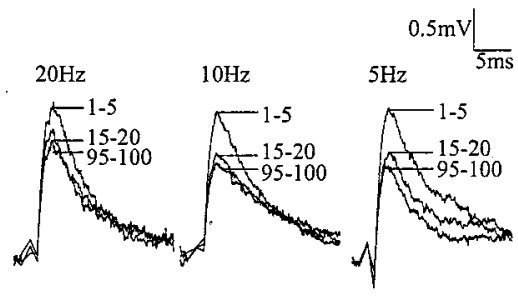

a plateau level early in the spike train provides further evidence against a simple depletion mechanism underlying the depression.

The inverse relationship between stimulation frequency and depression (Fig. 1 $A-D$; Parker and Grillner, 1999) suggests that depression is opposed by higher frequency activity. If so, it should thus be possible to reverse the depression by increasing the stimulation frequency. This was examined using a continuous train of spikes in which the stimulation frequency alternated between 5 and $20 \mathrm{~Hz}$ every 20 spikes $(n=5)$. Five hertz stimulation evoked the usual significant plateau level of depression to $\sim 50 \%$ of control by the tenth spike in the train. In each case, however, the depression was reversed when $20 \mathrm{~Hz}$ stimulation began, the EPSP typically recovering to the control value within the first three spikes (mean, $2.4 \pm 1.1$ spikes; Fig. $1 E$ ). The EPSP amplitude during the $20 \mathrm{~Hz}$ train stayed at the $20 \mathrm{~Hz}$ plateau level but returned to the $5 \mathrm{~Hz}$ level when $5 \mathrm{~Hz}$ stimulation resumed (Fig. 1E). This pattern continued essentially unaltered over 1000 consecutive EPSPs (Fig. $1 E$ ) and effectively rules out a simple depletion model of depression, because this would prevent the reversal of the depression.

\section{Dependence of the depression on changes in intracellular and extracellular calcium levels}

Because depletion alone cannot account for the depression, other potential contributory mechanisms were investigated (see intro- ductory remarks). The calcium dependence was examined initially, to investigate the role of direct calcium-dependent effects, as well as those caused by associated changes in release probability (Katz, 1966). Low-calcium Ringer's solution (see Materials and Methods) reduced the amplitude of low frequency-evoked EIN EPSPs to $55 \pm 17 \%$ of control $(n=7 ; p<0.001)$, consistent with a reduction in release probability. During spike trains, however, low-calcium Ringer's solution significantly reduced the depression at each frequency $(p<0.05)$ and could cause significant facilitation over Train $_{2-5}$ at 10 and $20 \mathrm{~Hz}(p<0.05$; Fig. 2 Ai, Aii; note that the traces are adjusted so that the initial EPSP amplitudes are the same) but nonsignificant facilitation over $\operatorname{Train}_{2-5}$ at $5 \mathrm{~Hz}(p>0.05$; data not shown). Although the facilitation at 10 and $20 \mathrm{~Hz}$ had recovered to control by the end of the spike train, no significant depression developed, thus preventing examination of the effect of low-calcium Ringer's solution on recovery. Depression, albeit at a significantly reduced level, was evoked over Train $_{11-20}$, at $5 \mathrm{~Hz}$, the recovery from depression being reduced to $\sim 80 \%$ of that in control (Fig. $2 D$ ).

Although the results shown in Figure 1 rule out a simple depletion model of depression, the effect of low-calcium Ringer's solution is consistent with a potential contribution of depletion, because lowering the release probability will reduce the amount of transmitter released by each spike, thus delaying depletion and 


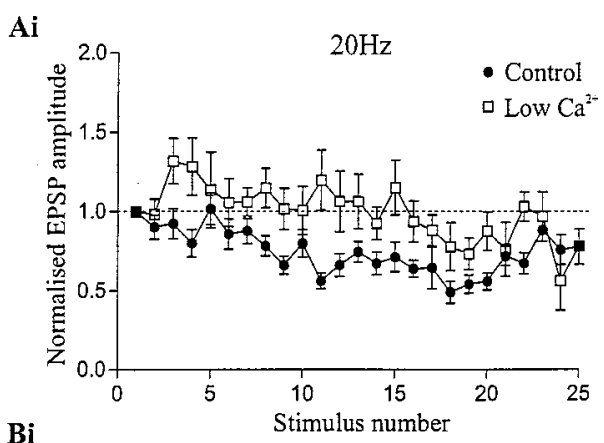

Aii

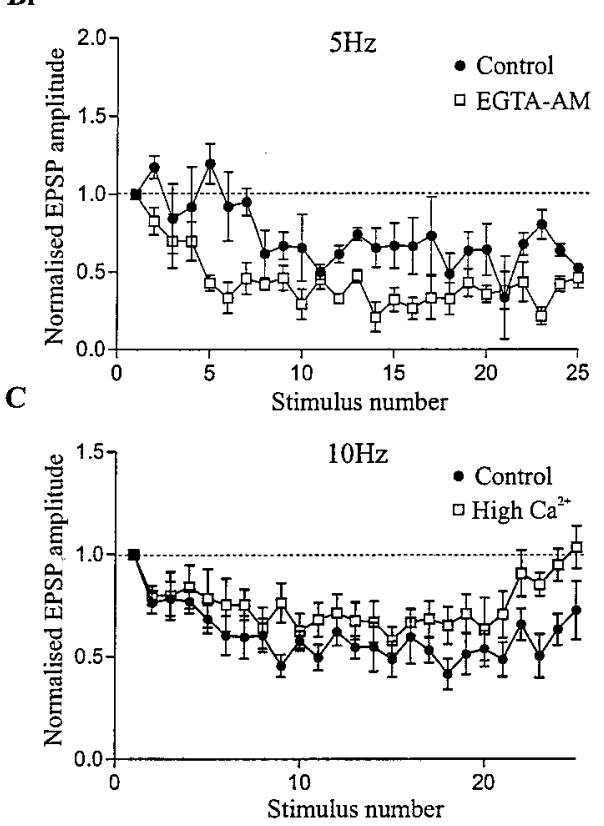

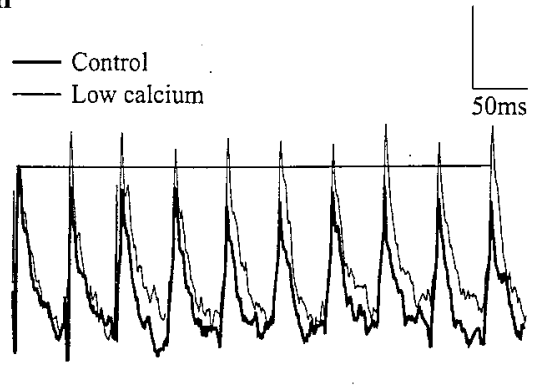

Bii
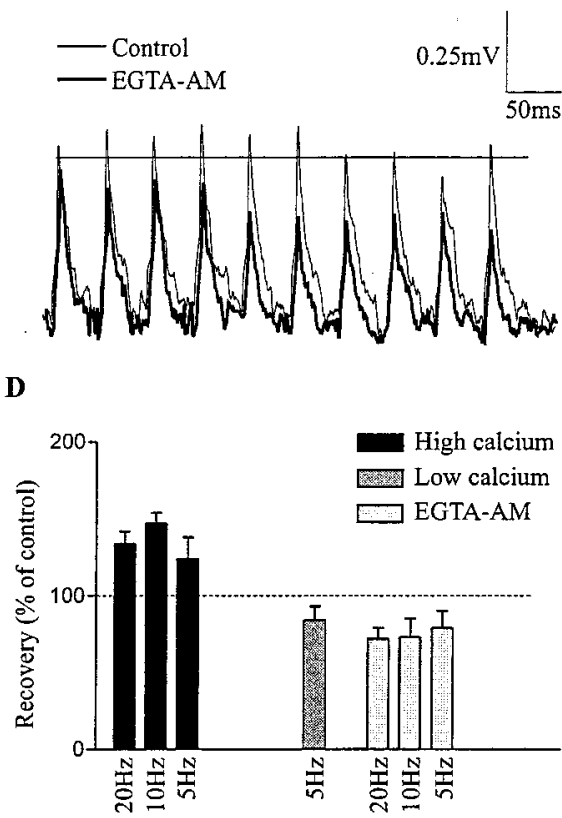

Figure 2. The effects of altering intracellular and extracellular calcium levels on the depression of EIN inputs. $A i$, Graph of the plasticity of EIN inputs evoked at $20 \mathrm{~Hz}$ in control and in the presence of low-calcium Ringer's solution, showing reduced depression/facilitation of EIN inputs when calcium levels were lowered $(n=7)$. In all graphs, control is indicated by black circles, and the relevant treatment by white squares. EPSPs numbered 21-25 are test EPSPs used to measure the recovery from depression. These were given $200 \mathrm{msec}, 700 \mathrm{msec}, 1.2 \mathrm{sec}, 2 \mathrm{sec}$, and $3 \mathrm{sec}$ after the end of the spike train. Aii, Traces showing the first ten spikes in a train in control (thick line), and in low-calcium Ringer's solution (thin line). The amplitude of the initial EPSP in low-calcium Ringer's solution has been scaled to match that in control, to aid comparison of the plasticity during the train. The scale bar is $0.5 \mathrm{mV}$ for control, and $0.3 \mathrm{mV}$ for low-calcium. Bi, Graph of EIN inputs to a motor neuron at $5 \mathrm{~Hz}$, showing enhanced depression during the train in the presence of the intracellular calcium chelator EGTA-AM (20 $\mu \mathrm{M} ; n=5$ ). Bii, The first ten EPSPs in a $20 \mathrm{~Hz}$ train are displayed, showing the enhanced depression in the presence of EGTA-AM (thick line). Note that in this experiment, in which the recording from the EIN was kept for $>1 \mathrm{hr}$, the amplitude of the initial EPSP in the train was not affected by EGTA-AM. $C$, Graph of EIN inputs at $10 \mathrm{~Hz}$ in control and in high-calcium Ringer's solution, showing the reduced depression when extracellular calcium levels were increased $(n=$ 7). Note also the faster recovery from depression in high-calcium Ringer's solution. D, Graph showing the effects of low-calcium Ringer's solution $(n=7)$, EGTA-AM $(n=5)$, and highcalcium Ringer's solution $(n=7)$ on the recovery from depression. To measure recovery, EPSP amplitudes in response to the test pulses at the end of the stimulation train were averaged, and the recovery expressed as percentage of that that occurred in control. the associated depression. The relationship between release probability and depression was thus examined further by investigating the influence of the initial EPSP amplitude (assumed to reflect release probability) on the plasticity expressed during different parts of the spike train (Fig. $3 \mathrm{Ai}-\mathrm{Ci}$; see Materials and Methods). At each frequency ( $n=35$ pairs), the correlations were weak and usually insignificant, reflecting depression with smaller initial EPSPs and facilitation or reduced depression with larger initial EPSPs $\left(\right.$ Train $_{2-5}: 20 \mathrm{~Hz}, r^{2}=0.12, p>0.05 ; 10 \mathrm{~Hz}, r^{2}=0.08, p>$ $0.05 ; 5 \mathrm{~Hz}, r^{2}=0.05, p>0.05$ Train $_{6-10}: 20 \mathrm{~Hz}, r^{2}=0.12, p>$ $0.05 ; 10 \mathrm{~Hz}, r^{2}=0.15, p>0.05 ; 5 \mathrm{~Hz}, r^{2}=0.20, p<0.05$; Train $_{11-20}: 20 \mathrm{~Hz}, r^{2}=0.13, p>0.05 ; 10 \mathrm{~Hz}, r^{2}=0.22, p<0.05$; $\left.5 \mathrm{~Hz}, r^{2}=0.13, p>0.05\right)$. In addition to examining the depression over different parts of the spike train, the influence of release probability was also examined using paired pulse stimulation. In contrast to the relationship between the initial EPSP and the plasticity during spike trains, paired pulse stimulation resulted in significant correlations at each frequency $\left(20 \mathrm{~Hz}, r^{2}=0.19, p<\right.$ $0.05, n=55 ; 10 \mathrm{~Hz}, r^{2}=0.20, p<0.05, n=38 ; 5 \mathrm{~Hz}, r^{2}=0.28$, $p<0.05, n=34$; Fig. 3Aii-Cii).

The relationship between the initial EPSP amplitude and subsequent plasticity shown above suggests a relationship between low-calcium/low-release probability and depression. This could support the contribution of depletion to the depression or an active calcium-dependent inhibition of transmitter release. To investigate these possibilities further, the slow intracellular calcium chelator EGTA-AM $(20 \mu \mathrm{M})$ was used to reduce intracellular calcium levels. These experiments were complicated by the incubation time required for EGTA-AM levels to increase to a level where it exerts significant effects ( $\sim 1 \mathrm{hr}$; Parker et al., 1998). Because stable EIN recordings lasting $\geq 1 \mathrm{hr}$ are rare, in all but one case (Fig. 2Bii) control and EGTA-AM responses were examined in different pairs. Although not ideal because the plasticity of EIN inputs to motor neurons in control occurs reasonably consistently (Parker and Grillner, 1999; my unpublished observation), a significant effect of EGTA-AM should be apparent. The amplitude of low frequency-evoked EPSPs, and presumably release probability, was not significantly affected by EGTA-AM (mean control, $0.92 \pm 0.06 \mathrm{mV}$ vs mean EGTA, $0.88 \pm 0.075 \mathrm{mV} ; p>0.1, n=5)$, supporting its proposed lack of effect on fast synaptic transmission (Adler et al., 1991; Parker et al., 1998; but see, Borst and Sakmann 1996). However, EGTA-AM significantly enhanced the depression during the spike train, and in some cases could cause EPSP failures (data not shown), significant effects developing at each frequency by the end of Train $_{2-5}$ ( $p<0.05, n=5$; Fig. $2 B i$, Bii). EGTA-AM also significantly reduced the recovery from depression $(p<0.05, n=$ 5; Fig. 2D). Thus, although failing to affect release probability, reducing intracellular calcium levels enhanced the depression, an 

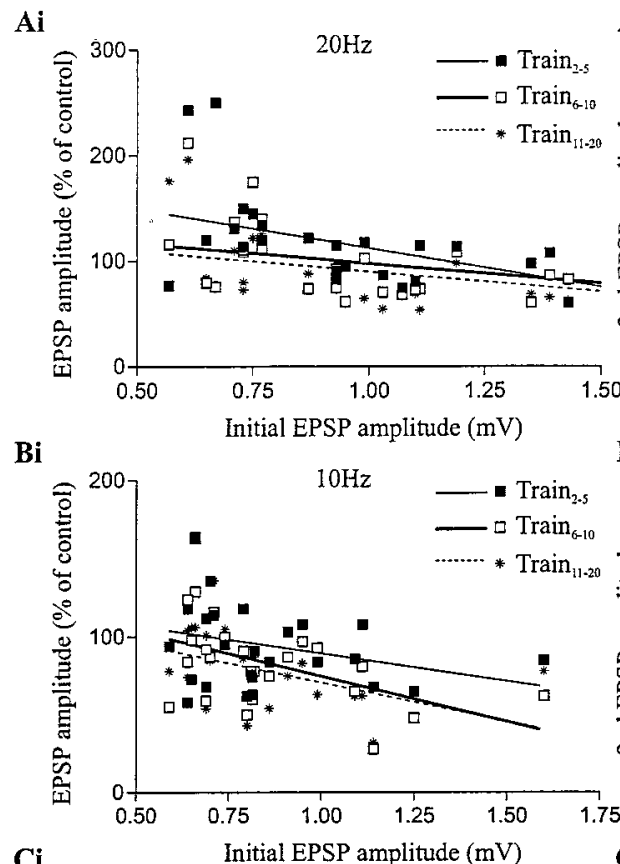

Figure 3. The influence of initial release probability (assumed to be related to the initial EPSP amplitude) on the depression of EIN inputs. In $\mathrm{Ai}-\mathrm{Ci}$, the initial EPSP amplitude was plotted against the averaged EPSP over the second to fifth $\left(\operatorname{Train}_{2-5}\right)$, sixth to tenth $\left(\operatorname{Train}_{6-10}\right)$, and eleventh to twentieth $\left(\right.$ Train $\left._{11-20}\right)$ EPSPs in the train (see Fig. 2 for the stimulus protocol). Data from 35 pairs are shown for stimulation at $20(\mathrm{Ai}), 10(\mathrm{Bi})$, and $5(\mathrm{Ci}) \mathrm{Hz}$. Relationship of the initial EPSP amplitude to the amplitude of the second EPSP during paired pulse stimulation at 20 $(n=55 ; A i i), 10(n=38 ; B i i)$, and $5(n=34$; Cii) Hz. The traces on the inset in Aii show the stimulus protocol and examples of the paired pulse effects.
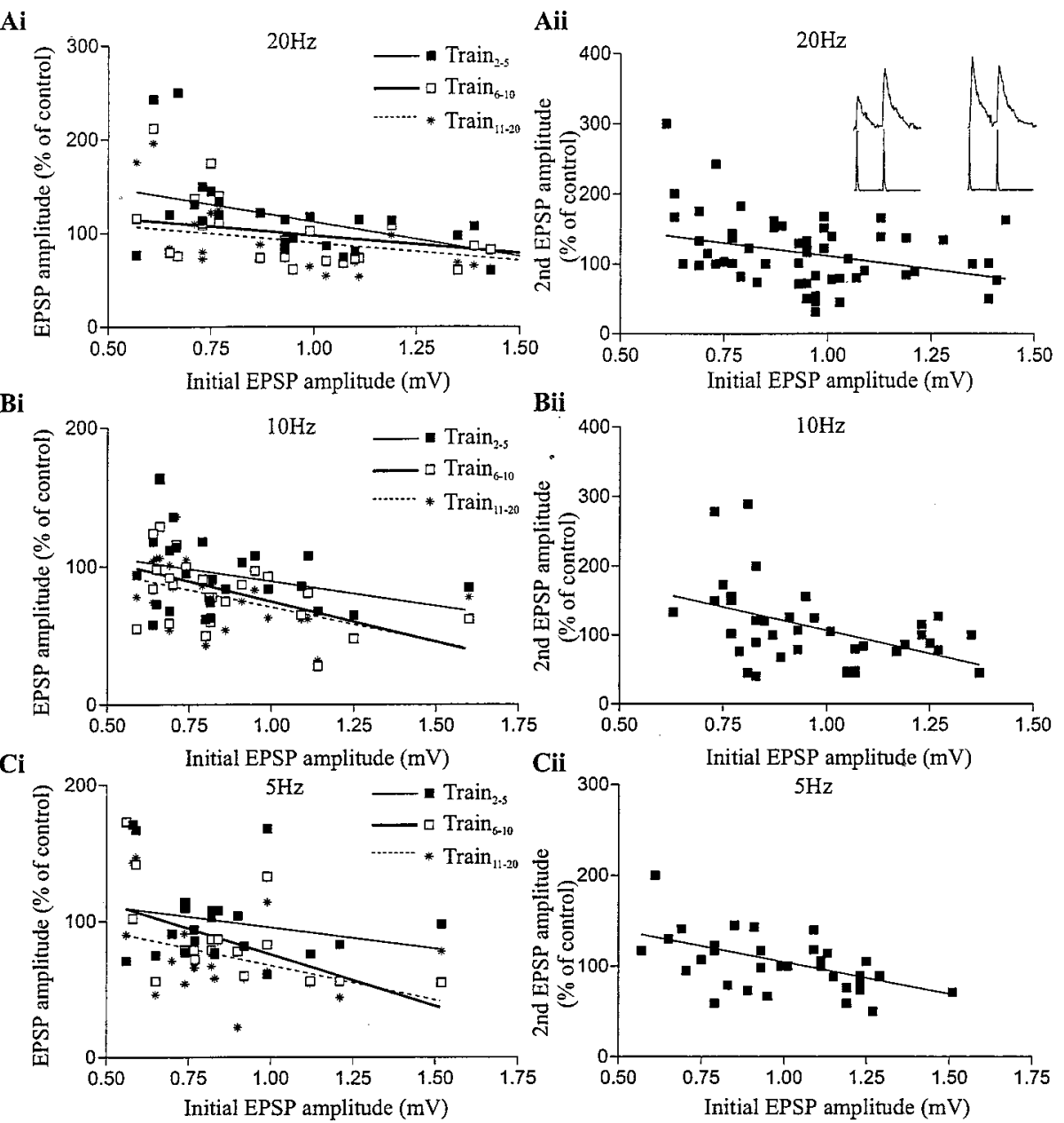

Bii

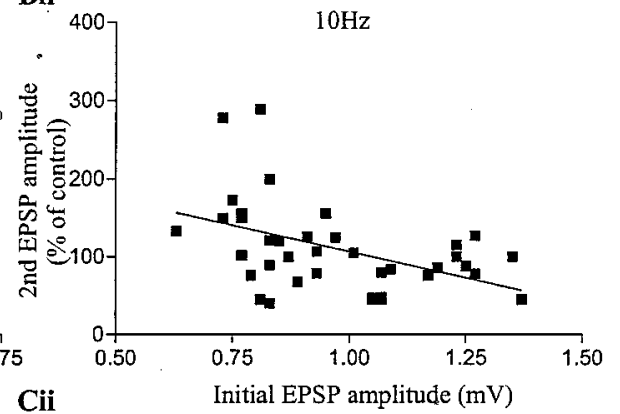

effect that suggests against active calcium-mediated inhibition of transmitter release.

As a final step in the analysis of the calcium dependence of the depression, the effect of increased extracellular calcium levels was examined. Although high-calcium Ringer's solution typically increases release probability (Katz, 1966), it did not significantly affect the amplitude of low-frequency EIN-evoked EPSPs (mean, $104 \pm 11 \%$ of control, $n=7 ; p>0.1$; data not shown). This suggests that the initial release probability was at a ceiling level, at least over the limited change in extracellular calcium levels used here. High-calcium Ringer's solution, however, slightly, but significantly, reduced the depression over $\operatorname{Train}_{6-10}$ and $\operatorname{Train}_{11-20}$ at 5 and $10 \mathrm{~Hz}(p<0.05 ; n=7$; Fig. $2 C)$, but not at $20 \mathrm{~Hz}(p>$ $0.05 ; n=7$; data not shown). In addition, high-calcium Ringer's solution significantly increased the recovery from depression at each frequency ( $p<0.05, n=7$; Fig. $2 D$ ). These effects again argue against active calcium-dependent inhibition underlying the depression.

To summarize these results, although the effects of low-calcium Ringer's solution and the influence of release probability suggest a contribution of depletion to the depression, the reduced or reversed depression at higher frequencies and the failure to increase depression with longer spike trains rules out a simple depletion mechanism. Instead, increased activity and intracellular calcium appear to actively oppose depression. Depletion may thus occur, which is countered by an activity and calciumdependent mechanism, possibly reflecting the replenishment of releasable transmitter stores (Stevens and Wesseling, 1998), the balance between these effects presumably determining the plateau level of depression.

\section{Contribution of changes in action potential properties to depression}

To provide further support for the proposed activity and calciumdependent mechanism underlying the depression, the contribution of other potential mechanisms were investigated (see introductory remarks). EIN action potentials during spike trains were examined to determine whether their activity-dependent modulation contributed to the depression (Klein et al., 1980; Bourque, 1990, 1991; Parker, 1995). This was done by recording from EIN axons within $50 \mu \mathrm{m}$ of the postsynaptic motor neurons $(n=7)$. Although the synaptic inputs depressed in each case (Fig. 4A, inset), there was no significant effect on the axonal spike amplitude $(p>0.05)$, duration $(p>0.05)$, or AHP at any frequency ( $p>0.05$; Fig. $4 A$, inset). Thus, although it is not possible to be certain that action potential modulation does not occur directly at release sites, there is no evidence to suggest that axonal spike modulation contributes to the plasticity of EIN inputs.

\section{mGluR-mediated inhibition of transmitter release}

Activation of metabotropic glutamate receptors (mGluR) can depress glutamatergic inputs (Forsythe and Clements, 1990). To test whether presynaptic mGluR activation affects the depression, the type III mGluR antagonist MAP4 (1 mM), which blocks 
A

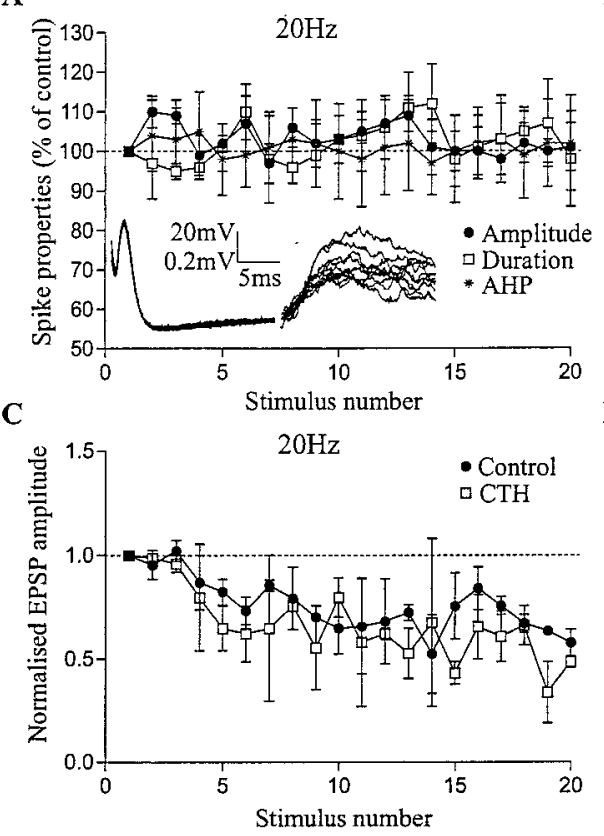

B

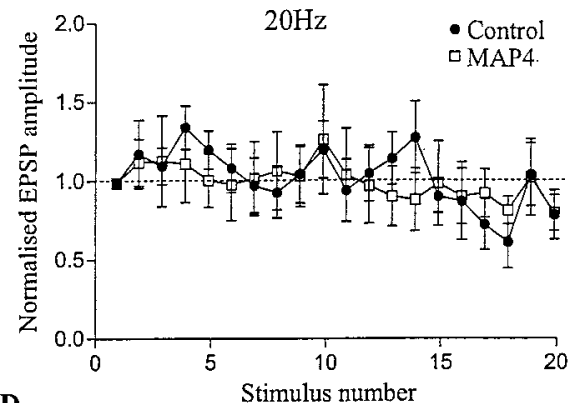

D

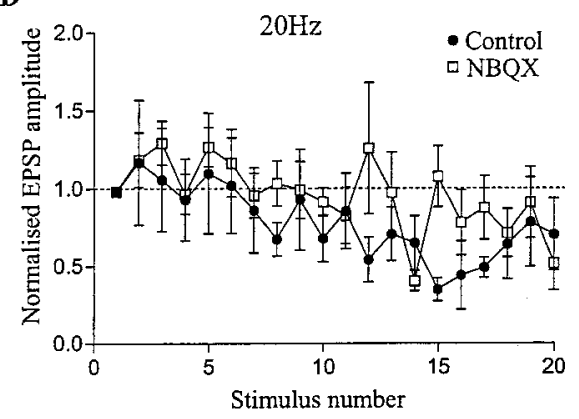

Figure 4. $A$, The plasticity of EIN inputs is not associated with modulation of the presynaptic axonal action potential amplitude, duration, or AHP $(n=7)$. For clarity, only every other action potential or EPSP is shown on the inset on the graph. $B$, The plasticity of EIN inputs to motor neurons is not associated with metabotropic glutamate receptor-mediated inhibition, shown by the failure of the mGluR antagonist MAP4 (1 $\mathrm{mM})$ to affect the synaptic input during a $20 \mathrm{~Hz}$ train $(n=4)$. $C$, Desensitization of AMPA receptors does not contribute to the depression of EIN inputs, because blocking desensitization with cyclothiazide $(100 \mu \mathrm{M})$ did not significantly affect the depression during a $20 \mathrm{~Hz}$ spike train $(n=7) . D$, The plasticity of EIN inputs is not associated with voltage-dependent changes in synaptic input sites. The graph shows $20 \mathrm{~Hz}$ EIN stimulation in control, and in the presence of the non-NMDA glutamate receptor antagonist NBQX $(1 \mu \mathrm{M} ; n=4)$, which reduced the EPSP amplitude to $\sim 60 \%$ of control, and thus reduced the postsynaptic depolarization during the spike train.
L-AP-4-mediated inhibition of reticulospinal synaptic transmission in the lamprey (Krieger et al., 1996), was used. MAP4 failed to affect the depression of synaptic inputs during the spike train at $5-20 \mathrm{~Hz}(n=4 ; p>0.1$; Fig. $4 B)$, suggesting that mGluRmediated modulation via type III receptors does not affect EIN inputs under these conditions. However, MAP4 could increase the amplitude of low frequency-evoked EIN inputs $(n=3$ of 4$)$, supporting the presence of endogenous mGluR-mediated modulation in the spinal cord (Krieger et al., 1998).

\section{Role of glutamate receptor desensitization in the depression}

In addition to the presynaptic effects examined above, postsynaptic contributions were also examined (see introductory remarks). AMPA receptor desensitization can depress glutamatergic EPSPs (Trussell et al., 1993; Otis et al., 1996). Because depression is inversely related to the stimulation frequency, desensitization is unlikely to contribute to the depression. Its role was examined directly, however, by blocking AMPA receptor desensitization with cyclothiazide (CTH; Vyklicky et al., 1991). CTH (100 $\mu \mathrm{M}$; $n=7$ ) did not affect the amplitude or duration of low frequencyevoked EPSPs ( $p>0.05 ; n=7$; Hjelmstad et al., 1999) or the plasticity of EIN inputs during spike trains ( $p>0.05 ; n=7$; Fig. $4 C$ ), suggesting that significant desensitization does not occur under these conditions.

\section{Contribution of postsynaptic voltage-dependent conductances to the depression}

Finally, dendritic voltage-activated conductances can influence synaptic inputs during spike trains (Johnston et al., 1996; Cash and Yuste 1999). The potential involvement of dendritic conductances in the plasticity of EIN inputs was thus investigated. This was initially examined by current injection $( \pm 2 \mathrm{nA})$ into the somata of postsynaptic motor neurons (mean soma depolarization, $27 \pm 7 \mathrm{mV}$; mean hyperpolarization, $32 \pm 5 \mathrm{mV}$ ). Current injection did not significantly affect the plasticity of EIN inputs $(n=8 ; p>0.05$; data not shown), suggesting that postsynaptic conductances do not contribute to the depression. Because it could be argued that current injection did not significantly affect the membrane potential at distal input sites, the glutamate receptor antagonist NBQX was also used. NBQX (1 $\mu \mathrm{M})$ reduced the amplitude of low frequency-evoked synaptic inputs to $59 \pm 4 \%$ of control ( $p<0.05$; data not shown), and will therefore reduce the postsynaptic depolarization during the train. Unless there was a marked differential distribution of NMDA and non-NMDA receptors between the dendrites and soma, of which there is no evidence for in the lamprey, NBQX should affect the activation of voltage-dependent dendritic conductances (Varela et al., 1997). NBQX did not, however, significantly affect the plasticity during spike trains $(n=4 ; p>0.05$; Fig. $4 D)$. This result, and that of experiments using current injection, thus suggests that dendritic conductances do not contribute to the plasticity of EIN-evoked EPSPs.

\section{The plasticity of EIN inputs during spike bursts}

The above results rule out a role for action potential- and mGluRmediated modulation or postsynaptic voltage or AMPA receptor desensitization in the depression, supporting the presence of the combined depletion and activity- and calcium-dependent mechanism proposed above. However, although the above analysis provides information on the depression of EIN inputs and its possible underlying mechanism, the single spike trains used above do not mimic interneuron spiking during network activity, where repetitive bursts of spikes are evoked at frequencies of $5-30 \mathrm{~Hz}$ (see Materials and Methods). In addition, to cover the physiological range of the network output, these bursts need to be evoked at interburst intervals of $\sim 50 \mathrm{~ms}$ to $2.5 \mathrm{sec}$ (Brodin et al., 1985). Although significant depression of EIN inputs to motor neurons does not usually develop over the first five spikes in a 20 spike train (Parker and Grillner, 1999), it was important to determine whether depression accumulated over repeated spike bursts (Manor et al., 1997). This analysis also allowed the relevance of the proposed activity- and calcium-dependent mechanism to be examined further. 
Figure 5. Effects of burst stimulation on the plasticity of EIN inputs. Bursts of five EIN spikes evoked at 20 and $5 \mathrm{~Hz}$ are shown, the interburst interval being $500 \mathrm{msec}$ and $2 \mathrm{sec}$, respectively. $\mathrm{Ai}$, Reliability of EIN inputs during $20 \mathrm{~Hz}$ bursts. The data on this graph is from one experiment in which 500 bursts were evoked. In this and subsequent graphs, the average of the first five (black circles) and last five (white squares) bursts is indicated, together with the average of all bursts (dashed line), to show the reliability of the input over repeated bursts. Aii, Traces showing EIN bursts from a different experiment to that shown in Ai. The numbers at the side of the traces indicate the number of the first burst in each sweep. Note the remarkably little variation in EPSP amplitudes over repeated bursts in this experiment. Bi, Amplitude of EPSPs evoked during $5 \mathrm{~Hz}$ burst stimulation. In this experiment, the EPSP amplitude depressed somewhat over repeated bursts. The data are from an experiment in which 200 bursts were evoked. Bii, Traces from another experiment, in which $5 \mathrm{~Hz}$ burst stimulation did not result in any gradually accumulating depression. The numbers at the side of the trace indicate the number of the burst. $C i$, Graph showing the effects of burst stimulation $(n=200)$ of two spikes at $30 \mathrm{~Hz}$ every $120 \mathrm{msec}$. This approximates the upper end of the interneuron spiking and bursting range. This stimulation also failed to cause depression of the EIN input to a motor neuron. Cii, Traces showing the failure of depression to develop during $30 \mathrm{~Hz}$ burst stimulation in a different experiment to that shown in $\mathrm{Ci}$.
Ai

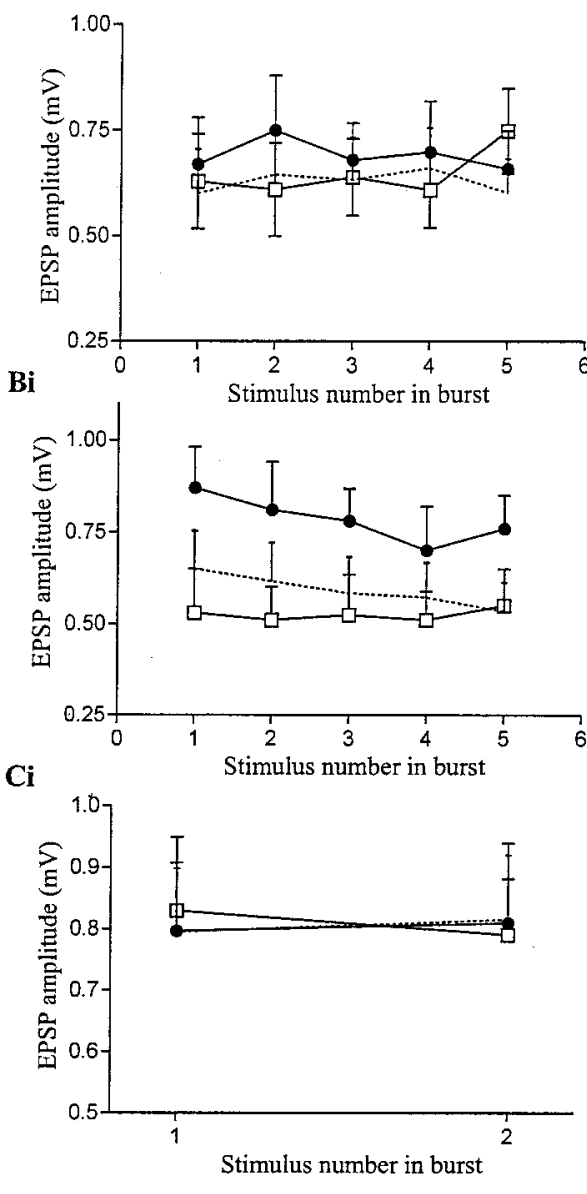

Aii
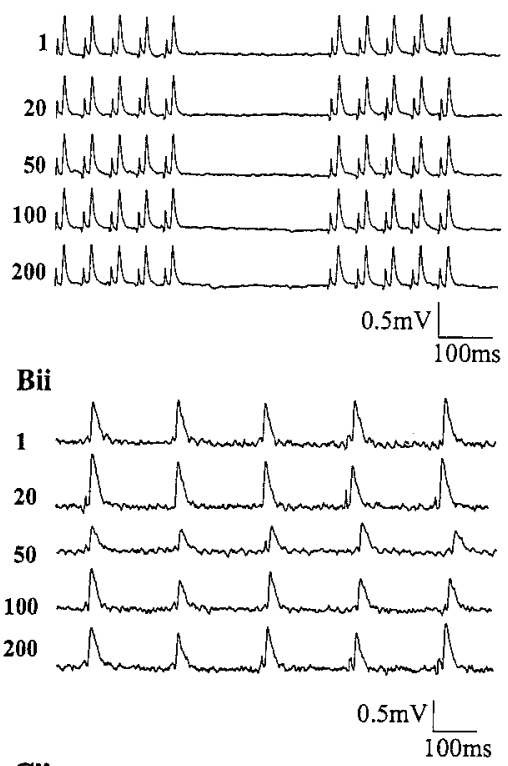

Cii
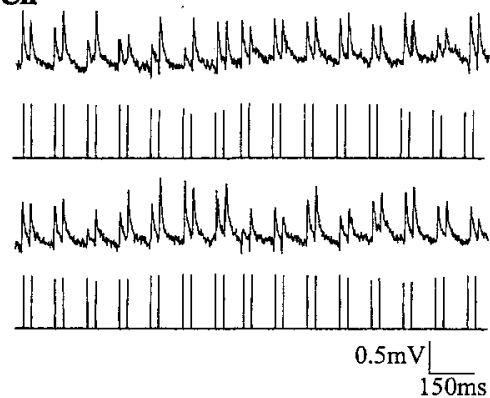

Experiments were initially performed using bursts of five spikes at 5, 10, and $20 \mathrm{~Hz}$, which were evoked at interburst intervals of $2 \mathrm{sec}, 1 \mathrm{sec}$, and $500 \mathrm{msec}$, respectively. Although EPSP amplitudes could fluctuate, trains of 50 bursts at $20 \mathrm{~Hz}$ did not evoke significant accumulative depression of the amplitude of the first EPSP in each burst $(n=26$ of $28 ; p>0.05)$ or of the summed EIN input during each burst ( $n=25$ of $28 ; p>0.05)$, the latter result reflecting the lack of an effect on the synaptic input over each burst. This stability of EIN inputs was maintained even when up to 500 bursts were given (i.e., 2500 spikes; $n=3$; Fig. $5 A i, A i i)$. The initial EPSP and summed synaptic input also did not depress significantly with spike bursts at lower stimulation frequencies $(250-2500$ spikes; $10 \mathrm{~Hz}, n=9$ of $10, p>0.05 ; 5 \mathrm{~Hz}, n=$ 9 of 13, $p>0.05$; Fig. 5Bii), although at $5 \mathrm{~Hz}$ gradual depression could develop in some experiments $(n=4$ of 13 ; Fig. $5 B i)$. These results show that in contrast to single spike trains, EIN inputs during repetitive burst stimulation show little depression, even though many more EPSPs are evoked. To examine the limit to which reliable synaptic transmission could be maintained, the upper end of the interneuron and network activity range was simulated. Bursts of two spikes at $30 \mathrm{~Hz}$ (the upper limit for the frequency of interneuron spiking during network activity; Buchanan and Cohen, 1982; Buchanan and Kasicki., 1995) were evoked every $120 \mathrm{msec}$ (i.e., $\sim 9 \mathrm{~Hz}$, the upper limit for the frequency of network burst activity; Brodin et al., 1985). Although the input could vary during bursts, this stimulation again failed to evoke gradual accumulating depression of the EPSP when delivered over 200 successive bursts $(n=400$ EPSPs; $p>$ $0.05, n=5$; Fig. 5Ci,Cii).

The lack of depression with burst stimulation supports the presence of an activity-dependent mechanism that maintains reliable transmitter release. This was examined further by evoking single spikes at the relevant interburst interval (i.e., $2 \mathrm{~Hz}$ at 20 $\mathrm{Hz}, 0.5 \mathrm{~Hz}$ at $5 \mathrm{~Hz}$ ) and comparing the amplitude of these EPSPs to the initial EPSPs over successive bursts at 20 or $5 \mathrm{~Hz}$. Single spikes tended to result in significantly greater depression by the end of the train than the initial EPSPs in repetitive spike bursts (20 Hz burst compared to $2 \mathrm{~Hz}$ train, $p<0.05, n=14$, Fig. 6 Ai,Aii; $5 \mathrm{~Hz}$ burst compared to $0.5 \mathrm{~Hz}$ train, $p<0.05, n=7$, Fig. $6 B i, B i i)$, suggesting that burst activity is important to the maintenance of transmitter release. This can also be seen when comparing the lack of depression over 400 EPSPs evoked in $30 \mathrm{~Hz}$ bursts at $\sim 9 \mathrm{~Hz}$ (Fig. 5Ci,Cii), to the significant depression evoked by $10-20$ spikes delivered in single spike trains at $5-10 \mathrm{~Hz}$ (Fig. 1).

Bursting, and thus interneuron activity, contributes to the maintenance of reliable synaptic transmission, accumulating depression over repetitive spike bursts presumably being prevented by the replenishment of transmitter stores in the interburst interval. To determine if this process is calcium-dependent, as suggested from the analysis of spike trains (Fig. 2), the effects of the slow intracellular calcium chelator EGTA-AM $(20 \mu \mathrm{M})$ were examined on burst-evoked inputs. In most of the experiments, different EINs again had to be compared in control and in 
$\mathrm{Ai}$

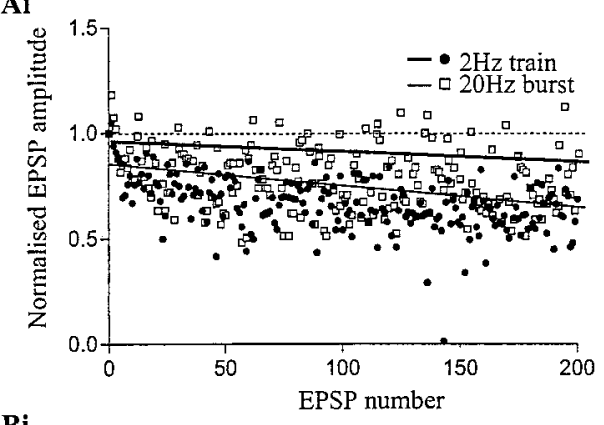

Bi

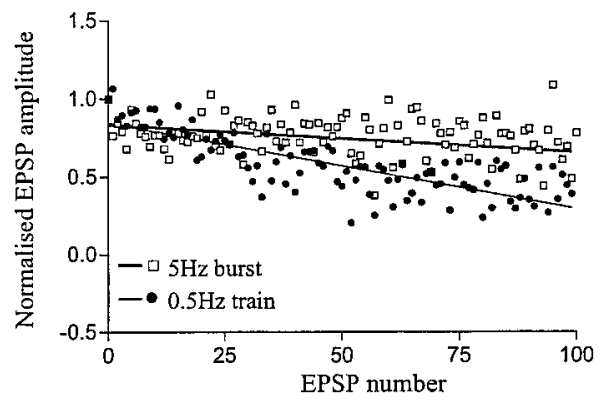

Aii

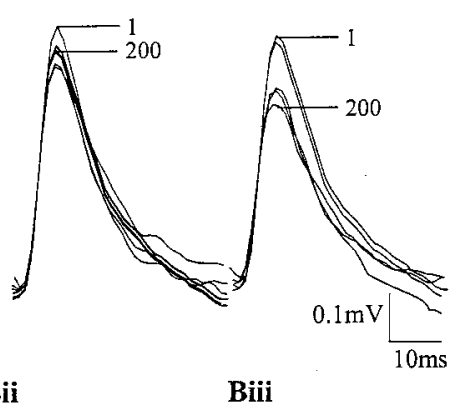

Bii

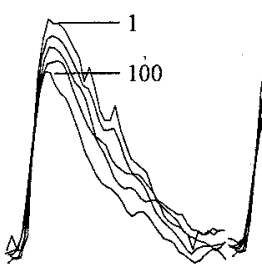

Aiii

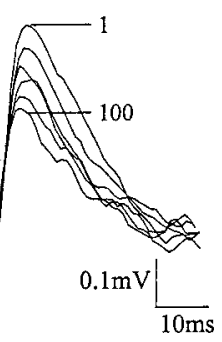

Figure 6. The maintenance of burst transmission is activity-dependent. $A i$, Graph showing the amplitude of the initial EPSP in each burst from an experiment in which $20 \mathrm{~Hz}$ burst stimulation was evoked (white squares) and the amplitude of 200 successive EPSPs evoked every $500 \mathrm{msec}$ (i.e., $2 \mathrm{~Hz}$, the interburst interval of $20 \mathrm{~Hz}$ burst stimulation; black circles). Two hundred EPSPs are shown in each condition for comparison. The initial EPSP of each burst fluctuates, but does not gradually depress, whereas single EPSPs evoked at $2 \mathrm{~Hz}$ depressed over the first 50 bursts. Aii, Traces showing the amplitude of sample initial EPSPs from a $20 \mathrm{~Hz}$ burst stimulation experiment, with the first and last initial EPSPs labeled. Aiii, Traces showing sample EPSPs from a 2 $\mathrm{Hz}$ train, again with the first and last EPSPs labeled. $B i$, Graph showing the amplitude of the initial EPSP in each burst over $1005 \mathrm{~Hz}$ bursts (white squares) and the amplitude of successive EPSPs evoked every 2 $\mathrm{sec}$ (i.e., the interburst interval of $5 \mathrm{~Hz}$ burst stimulation; black circles). Notice again the initial EPSP in the burst depressed less than that over the $0.5 \mathrm{~Hz}$ train. Bii, Traces showing the amplitude of initial EPSPs in the bursts, with the first and last initial EPSP labeled. Biii, EPSPs during the $2 \mathrm{~Hz}$ train, with the first and last EPSPs in the train labeled. The lines on the graphs are linear regressions.

Figure 7. The effect of EGTA-AM on EIN inputs in response to burst stimulation. $A i$, Control response to $20 \mathrm{~Hz}$ burst stimulation ( $n=50$ bursts). Aii, The same EIN-MN pair in the presence of the intracellular calcium chelator EGTA-AM $(20 \mu \mathrm{M})$. Note that the amplitude of the EPSPs during the first burst were not affected by EGTA-AM (compare the traces indicated by black circles on both graphs), but that there was a gradual reduction of the EPSP amplitude over successive bursts in EGTA-AM ( $n=50$ bursts). $B$, The initial EPSP in each burst from the graphs in $A i$ and $A i i$ are shown in control and in EGTA. The amplitudes of the initial EPSPs in the first bursts have been normalized. In control, the EPSP fluctuates around the amplitude of the first EPSP, whereas in EGTA-AM the EPSP successively depresses to reach a plateau level of $\sim 50 \%$ between the fifth and tenth bursts. $C$, Traces showing the synaptic input in a motor neuron after $20 \mathrm{~Hz}$ burst stimulation in the presence of EGTA-AM in a different experiment to that shown in $A$ and $B$, but again in an experiment where the recording from the EIN was held in excess of $1 \mathrm{hr}$. The synaptic input during the burst in this experiment was severely disrupted by EGTA-AM. The first trace in each case shows the initial two bursts. Subsequent traces show two bursts taken at different times during repetitive burst stimulation. The numbers at the side of each trace indicate the number of the first burst in the sweep.

EGTA-AM, although in three experiments the same pair could be examined in both conditions. EGTA-AM again failed to significantly affect the amplitude of low frequency-evoked EPSPs (i.e., the initial EPSP in the first burst; see above). However, it significantly depressed synaptic transmission during bursts at 5 $\mathrm{Hz}(n=7$ of $9, p<0.05)$ and $20 \mathrm{~Hz}(n=8$ of $11, p<0.05$; Fig. $7 \mathrm{Ai}$,Aii), and in extreme cases caused many EPSP failures (Fig. $7 C$ ). Synaptic transmission usually became depressed or disrupted between the fifth and tenth bursts, i.e., between the twenty-fifth and fiftieth EPSPs (Fig. 7B; but see Fig. $7 C$ ). This is a longer time than that required for the development of depres- sion during single trains of 20 spikes and may reflect residual replenishment occurring during the interburst phase caused by incomplete buffering of calcium by EGTA.

\section{The role of calcium-activated second messengers in the maintenance of burst transmission}

The effect of EGTA-AM supports the calcium dependence of reliable EIN synaptic transmission. Calcium could either act directly to maintain transmitter release or through second messenger-mediated pathways. For example, protein kinase $\mathrm{C}$ (PKC; Smith, 1999), myosin light chain kinase (MLCK; Ryan, 
Figure 8. The effects of second messenger antagonists on bursting transmission. $A i$, Graph showing the plasticity of EIN inputs to a motor neuron in response to burst stimulation of the EIN at $20 \mathrm{~Hz}$ in the presence of the protein kinase $\mathrm{C}$ antagonist chelerythrine $(10 \mu \mathrm{M}$; compare with Figs. $5 A i, 7 A i)$. Aii, The amplitude of the initial EPSP in each burst from a different experiment to that in $A i$, again showing no significant depression of the initial EPSP amplitudes in the presence of chelerythrine. $B i$, Graph showing the plasticity of EIN inputs during bursts of EPSPs at $20 \mathrm{~Hz}$ in the presence of the myosin light chain kinase inhibitor ML-7 $(10 \mu \mathrm{M})$. Bii, Data from a different experiment to that in $B i$, again showing no significant effect of ML-7 on the amplitude of the initial EPSP in the bursts. $\mathrm{Ci}$, Twenty hertz burst stimulation in the presence of the CAM kinase inhibitor KN-62 (10 $\mu \mathrm{M})$. Cii, The amplitude of the initial EPSP in each burst in the presence of $\mathrm{KN}-62$, again showing no effect on the amplitude of the initial EPSPs. The lines drawn on the graphs in $\mathrm{Aii}-\mathrm{Cii}$ are linear regression lines.

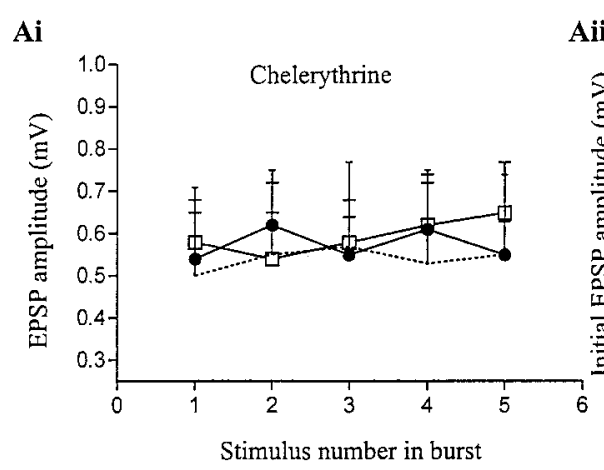

Aii ${ }^{0.8} \quad$ Chelerythrine
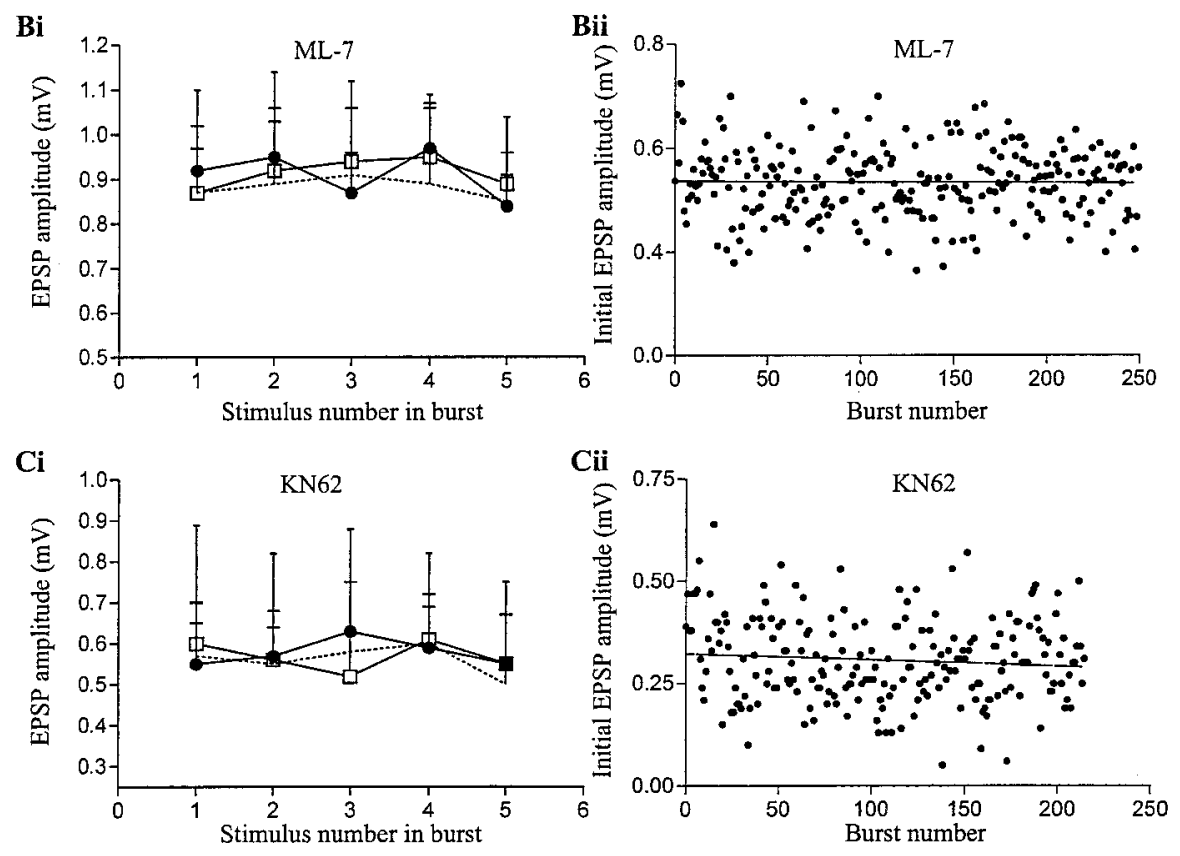

1999), and calmodulin-dependent protein kinase (CAM kinase; Llinas et al., 1991), are all activated by calcium and have been suggested to contribute to the regulation of releasable transmitter stores in neurons and endocrine cells, and could thus provide a link between calcium entry and the maintenance of EIN-evoked transmitter release. The contribution of these second messengers was examined using specific inhibitors. The PKC inhibitor chelerythrine at a concentration that blocks PKC-mediated effects in the lamprey (10 $\mu \mathrm{M}$; Parker et al., 1998) did not significantly affect the amplitude of low frequency-evoked EPSPs or the pattern and reliability of synaptic inputs during bursts $(n=4$ of $4, p>0.1$; Fig. 8Ai,Aii). The specific MLCK inhibitor ML-7 (10 $\mu \mathrm{M}$; Ryan, 1999) also failed to significantly affect the amplitude of low frequencyevoked EPSPs or the reliability of synaptic transmission during spike bursts ( $n=4$ of $5, p>0.05$; Fig. $8 B i, B i i)$, although in one case the amplitude of low frequency-evoked EPSPs was significantly reduced, and burst transmission was disrupted (data not shown). Finally, the CAM kinase inhibitor KN62 (10 $\mu \mathrm{M})$ also did not significantly affect the amplitude of low frequency-evoked EPSPs $(n=4 ; p<0.05)$ or synaptic transmission during spike bursts $(p>0.05$; Fig. $8 \mathrm{Ci}, \mathrm{Cii})$. These results thus fail to support a role for these second messengers in the maintenance of transmitter release, suggesting that calcium may act directly to regulate transmission.

In addition to examining the role of calcium-activated second messengers, the source of calcium required for maintaining trans- mitter release was examined. As in most other systems (Dunlap et al., 1995), transmitter release in the lamprey spinal cord appears to be mediated by $\mathrm{N}, \mathrm{P} / \mathrm{Q}$, or R-type calcium channels, with L-type channels playing no role (Krieger et al., 1999). Calcium entry through L-type channels, however, has been suggested to contribute to posttettanic potentiation in cultured hippocampal neurons (Jensen et al., 1999). The L-type calcium channel antagonist nimodipine (10-25 $\mu \mathrm{M}$; Krieger et al., 1999) did not affect the amplitude of the initial EIN-evoked EPSP in the bursts or the summed synaptic input during bursts $(n=5$ of $5, p>0.1$; data not shown), thus suggesting that L-type calcium channels do not underlie or maintain transmitter release from EINs. The calcium signal that promotes reliable transmitter release is thus linked to the calcium entering through $\mathrm{N}, \mathrm{P} / \mathrm{Q}$, or R-type channels to promote transmitter release, although potential release from intracellular stores cannot be ruled out.

\section{The plasticity of connections made by other interneurons during spike bursts}

The final aspect examined was how general the reliability of synaptic transmission was from other network interneurons during burst stimulation. The first connection examined was from EINs to inhibitory crossed caudal (CC) interneuron ( $n=4$; Fig. $9 A$ ). In a proportion of cells, this connection exhibits significant activity-dependent facilitation or depression over the first five spikes in a 20 spike train (my unpublished observation). Synaptic 
A

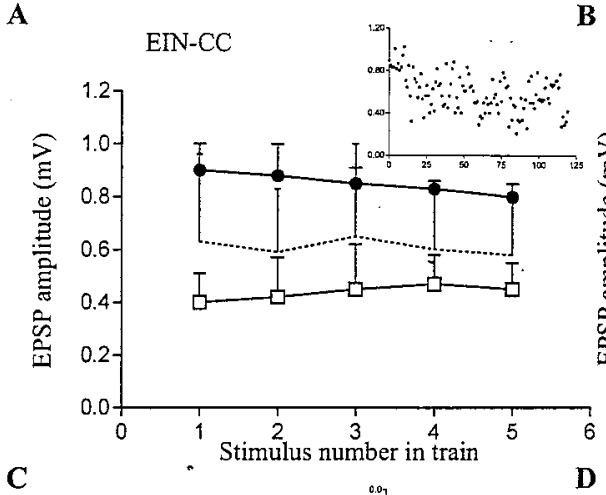

C

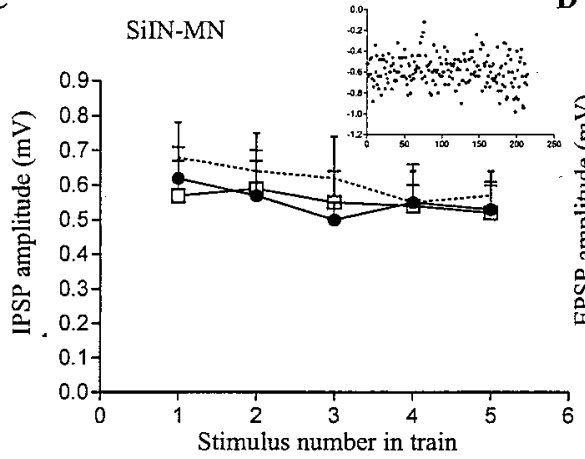

$\mathbf{E}$

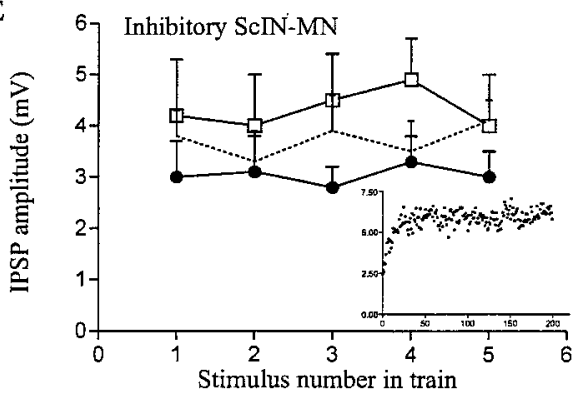

B
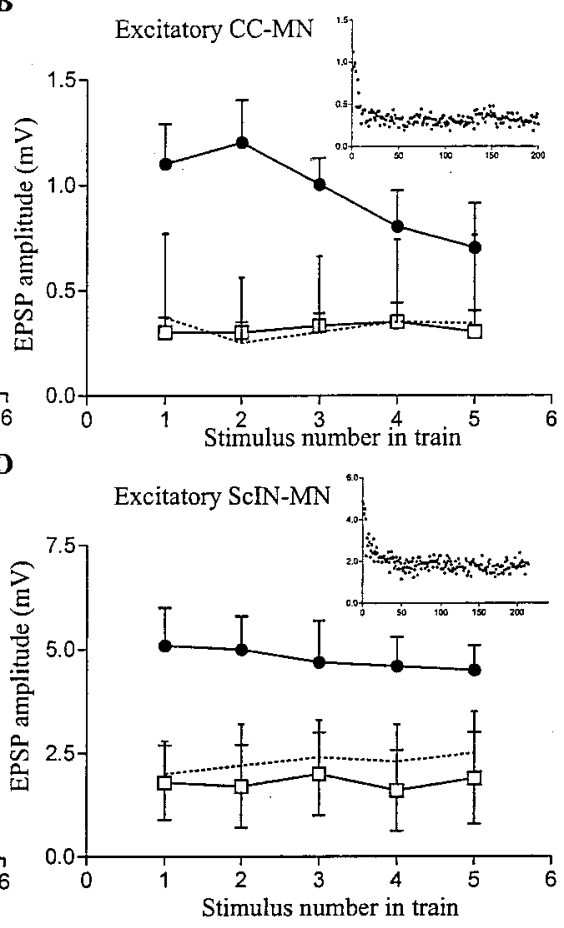

Figure 9. Responses of other spinal synaptic connections to burst stimulation. $A$, Plasticity of EIN inputs to an ipsilateral crossed caudal interneuron in response to spike bursts at $20 \mathrm{~Hz}$. The insets on all graphs show the amplitude of the initial EPSP in each burst, showing the accumulation of plasticity over repeated bursts. $B$, Plasticity of an excitatory crossed caudal interneuron in response to $20 \mathrm{~Hz}$ burst stimulation. The input depresses markedly over the initial bursts. Note on the inset graph the rapid and marked depression of the initial EPSP amplitude over successive bursts. $C$, Graph showing the input from an SiIN to a motor neuron during 20 $\mathrm{Hz}$ burst stimulation. Note the absence of depression over repeated bursts. $D$, Input from a small crossing interneuron to a contralateral motor neuron. As with excitatory CC interneurons, the input from the ScIN depresses rapidly over successive bursts. $E$, Input from an inhibitory ScIN to a contralateral motor neuron. In this case, the input facilitates over repeated bursts. Note that the inputs from the ScINs in these experiments were much larger than other interneuron connections. transmission over $20 \mathrm{~Hz}$ bursts did not occur consistently, however, significant depression developed between the tenth and twentieth bursts $(n=4 ; p<0.05)$ and then continued to gradually increase. The development of depression over subsequent bursts will make this connection functionally weak during even relatively short bursts of network activity. Connections from excitatory crossed caudal interneurons to motor neurons were also examined (Buchanan, 1982). This connection depresses markedly during single spike trains (Parker and Grillner, 1999). The input from these interneurons depressed to an even greater extent during burst stimulation, with plateau depression developing over the first $5-10$ bursts $(p<0.01$; Fig. 9B).

Connections from small ipsilateral inhibitory interneurons (SiIN) to motor neurons $(n=7)$ were also examined (Buchanan and Grillner, 1988). These neurons could play a significant role in the generation of segmental network activity (Rovainen, 1983; Buchanan and Grillner, 1988). Synaptic inputs occurred consistently during burst activity (Fig. 9C), no significant depression of the IPSP occurring with respect to the initial IPSP in each burst or the summed input during single bursts, when up to 200 bursts were given $(p>0.05)$. As with EINs, transmitter release from these interneurons will thus presumably occur reliably during prolonged rhythmic network activity.

The final connections examined were those made by small crossing interneurons with short axonal projections (ScIN; Ohta et al., 1991; Fagerstedt and Wallén 1992, 1993) onto motor neurons. Rovainen $(1983,1986)$ predicted that such neurons would play a role in the patterning of segmental activity, being likely candidates to mediate segmental reciprocal inhibition. The plasticity of these interneurons has been examined during single spike trains, excitatory inputs depressing markedly, whereas inhibitory inputs were not affected (my unpublished observations). As with the CC interneurons, with repetitive spike bursts, excitatory ScIN-evoked EPSPs depressed markedly over the first two bursts ( $n=3$ of 5 ; Fig. $9 D$ ), a plateau level of depression being reached between the fifth and tenth bursts. In the other two experiments, depression took longer to develop, only becoming significant between the twentieth and thirtieth bursts. Although inhibitory inputs showed no significant change during single trains of 20 spikes (my unpublished observations), this was not the case with spike bursts. Instead, the input consistently facilitated over repetitive bursts, significant effects developing to reach a plateau between the fifth and tenth bursts $(n=4$; Fig. $9 E)$. Note that excitatory and inhibitory ScIN inputs were much larger than is usual for network interneuron synaptic inputs.

\section{DISCUSSION}

The activity-dependent depression of glutamatergic inputs from EINs, which mediate excitation at the segmental level in the lamprey spinal cord (Buchanan et al., 1989), has been examined in 
this study. The results suggest that depression is caused by initial depletion of releasable transmitter stores, an effect that is opposed by an activity- and calcium-dependent mechanism at higher frequencies. This mechanism contributes to the maintenance of synaptic transmission during simulated network activity. By monitoring interneuron and synaptic activity, it can thus adapt transmitter release to different network outputs.

\section{Mechanisms underlying EIN depression}

Several factors could evoke the depression of EIN inputs. Of these, action potential modulation (Klein et al., 1980; Bourque, 1990, 1991; Parker, 1995), mGluR-mediated inhibition of transmitter release (Forsythe and Clements, 1990), AMPA receptor desensitization (Trussell et al., 1993; Jones and Westbrook, 1996; Otis et al., 1996), and voltage-dependent dendritic conductances (Johnston et al., 1996; Cash and Yuste, 1999; Cook and Johnston, 1999) do not appear to be important. However, the depression was reduced in low-calcium Ringer's solution and enhanced after larger initial EPSPs. These effects support transmitter depletion because low-calcium Ringer's solution reduces release probability (suggested by the reduced initial EPSP amplitude), thus delaying depletion of the releasable vesicle pool, whereas larger initial EPSPs (assuming they reflect increased transmitter release) should enhance depletion by using a larger proportion of the releasable pool.

Depletion alone, however, cannot account for the depression. The failure to increase depression with longer spike trains, the reduced or reversed depression at higher stimulation frequencies, the reduced depression in high-calcium Ringer's solution, and the enhanced depression when cytosolic calcium levels are reduced by EGTA-AM, are all incompatible with a simple depletion model. Active calcium-dependent inhibition of transmitter release, presynaptic calcium channel inactivation (Forsythe et al., 1998), and inhibition of the transmitter release machinery (Hsu et al., 1996) are also not compatible with these results. However, the results are consistent with initial depletion opposed by an ongoing activity and calcium-dependent mechanism, possibly related to the replenishment of the releasable transmitter pool (Zucker 1989; Stevens and Wesseling, 1998). Activity dependence is supported by the reduction or reversal of depression at higher stimulation frequencies, whereas calcium dependence is supported by the reduced depression in high-calcium Ringer's solution, but enhanced depression with EGTA-AM. The plateau level of depression during spike trains presumably reflects the equilibrium between depletion and maintenance mechanisms.

Activity-dependent mechanisms appear to promote reliable transmission during bursts that approximate assumed EIN spiking during network activity. In contrast to the depression during single trains of 20 spikes (Parker and Grillner, 1999), burst transmission occurred reliably over 500-2500 EPSPs. Bursts thus ensure reliable transmitter release (Lisman 1997). This reliability was also activity- and calcium-dependent, shown, respectively, by the depression evoked when single EPSPs were elicited at the interburst interval and the disruption of synaptic transmission by EGTA-AM.

Although the molecular mechanisms underlying the maintenance of EIN-evoked transmitter release are unknown, there is as yet no evidence to suggest the involvement of calcium-activated second messengers (for review, see Kamiya and Zucker, 1994). Calcium, apparently related to the calcium signal underlying transmitter release (i.e., through N, P/Q, and R channels; Krieger et al., 1999), may thus act directly. Calcium-mediated replenish- ment could occur either through vesicle mobilization from a reserve pool (Ryan, 1999) or endocytotic recycling (Klingauf et al., 1998). Although calcium triggers endocytosis in endocrine cells (Artalejo et al., 1994), action potential-evoked calcium entry is not necessary for endocytosis in lamprey glutamatergic reticulospinal axons (Gad et al., 1998), and in some systems, increased activity can actually reduce endocytosis (Thomas et al., 1994; von Gersdorff and Matthews 1994; Wu and Betz, 1996). Mobilization of vesicles from a reserve pool may thus be more relevant, although endocytosis presumably must also occur.

Increasing extracellular calcium levels did not affect low frequency-evoked EPSP amplitudes, suggesting that transmitter release operates at or near maximal sensitivity to calcium, at least over the calcium range used here. This is consistent with the absence of PSP failures from EINs and other network interneurons (my unpublished observations). Maximally efficient transmitter release at physiological calcium levels would be advantageous in rhythmic networks, where precise timing and coordination requires reliable transmitter release. High-calcium Ringer's solution also failed to affect the plasticity of EIN inputs at $20 \mathrm{~Hz}$, presumably because of the more effective replenishment at this frequency (Fig. 1).

\section{The time course of the proposed replenishment mechanism}

Depression during spike trains usually developed to a plateau level over $\operatorname{Train}_{5-10}$. A significant enhancement of the depression developed by the end of $\operatorname{Train}_{2-5}$ in EGTA-AM (Fig. 2Bi), with a similar delay occurring before significant effects of high-calcium Ringer's solution were seen (Fig. 2C). In addition, although there was no significant correlation between release probability and depression by the end of $\operatorname{Train}_{2-5}$, there was with paired-pulse stimulation, suggesting that replenishment may occur sometime during Train $_{2-5}$. However, with alternating stimulation frequencies (Fig. $1 E$ ) recovery of the depression occurred faster, between the second and third spikes in the train. However, in this case, the lack of an interval between trains may cause the proposed replenishment process to be activated at the start of $20 \mathrm{~Hz}$ stimulation. The proposed replenishment mechanism can thus develop by the fifth spike after the start of network activity, but may be faster during ongoing activity. Because network interneurons are assumed to fire up to five spikes during network activity (see Materials and Methods), this mechanism is tailored to the network requirements.

\section{Generality of the reliability of synaptic transmission}

No significant plasticity of EIN inputs to motor neurons occurs over Train $_{2-5}$, suggesting little contribution of plasticity to the patterning of network activity during locomotion (Parker and Grillner, 1999). Other synaptic connections, however, exhibit significant activity-dependent depression or facilitation during Train $_{2-5}$ (my unpublished observations). Activity-dependent synaptic plasticity could thus contribute to the coordination of locomotion if these connections form part of the locomotor network (Getting, 1989). However, depression must not accumulate over repetitive bursts, because this would result in changes, or even termination, of the network output over time. This may be useful under some conditions, but not for prolonged regular network activity. Although EIN and SiIN input to motor neurons exhibited consistent responses during burst stimulation, this was not true of all connections. In particular, inputs to and from CC interneurons depressed over repeated bursts. CC interneurons 
are proposed to mediate reciprocal inhibition in the locomotor network (Buchanan and Grillner, 1987; Grillner et al., 1998), although their role was, and is, uncertain (Rovainen, 1983, 1986; Buchanan, 1999; Buchanan and Kasicki, 1999; my unpublished observations). The accumulating depression over repetitive bursts further suggests against this role for $\mathrm{CC}$ interneurons in the segmental network. In contrast, large inhibitory inputs from ScINs (Fagerstedt and Wallén, 1992, 1993), which were suggested as potential candidates for segmental reciprocal inhibition (Rovainen 1983, 1986), facilitated over repeated spike bursts, a stable significant plateau being reached by the tenth burst. Excitatory inputs from these neurons, however, depressed rapidly with repeated bursts, and thus would not be expected to contribute to maintained network activity. Preliminary results suggest that excitatory ScINs receive monosynaptic inputs from sensory dorsal cells ( $n=2$; my unpublished observations). They may thus be sensory interneurons that transmit cutaneous inputs to the locomotor network (Rovainen, 1967).

The reliability of burst synaptic transmission may identify interneurons involved in patterning rhythmic network activity. If so, the results of this study support the proposed role of EINs in ipsilateral segmental excitation (Buchanan et al., 1989), SiINs in ipsilateral segmental inhibition (Buchanan and Grillner, 1988), and the ScINs in segmental reciprocal inhibition (Rovainen, 1983, 1986). As suggested by Rovainen (1983), this would suggest intersegmental, not segmental, roles for the LINs and CC interneurons.

\section{Contribution of replenishment mechanisms to network activity}

The lamprey locomotor network is active over a frequency range of $\sim 0.5-10 \mathrm{~Hz}$ during actual and fictive swimming (Wallén and Williams, 1984). Network interneurons typically fire up to five spikes at frequencies of 5-30 Hz. Longer bursts of spikes can occur (Buchanan et al., 1989, their Fig. 8; my unpublished observations), which may be relevant to different network outputs, for example postural adjustments, or motor programs during mating. The duration of network activity can vary from a few seconds when disturbed, hours when seeking prey, to weeks during migration. The EIN burst frequency, the intraburst frequency, and the intraburst and interburst duration, can thus vary markedly during the same or different network outputs. EINs, and other network neurons, must thus cope with a wide range of frequencies, patterns, and durations of network activity. Although extrapolating from the analysis of a single type of synapse in vitro to in vivo behavior is difficult, and other regulatory mechanisms may also contribute, the regulation of synaptic efficiency through a negative feedback mechanism activated by interneuron and synaptic activity, as suggested here, will evoke greater replenishment of the releasable vesicle pool when release is increased. By monitoring changes in synaptic activity, reliable transmitter release can thus occur over a wide range of EIN and network outputs.

\section{REFERENCES}

Adler EM, Augustine GJ, Duffy S, Charlton MP (1991) Alien intracellular calcium chelators attenuate neurotransmitter release at the squid giant synapse. J Neurosci 11:1496-1507.

Artalejo CR, Adams ME, Fox AP (1994) Three types of Ca2+ channel trigger secretion with different efficacies in chromaffin cells. Nature 367:72-75.

Borst JGG, Sakmann B (1996) Calcium influx and transmitter release in a fast CNS synapse. Nature 383:431-434.

Bourque CW (1990) Intraterminal recordings from the rat neurohypophysis in vitro. J Physiol (Lond) 421:247-262.
Bourque CW (1991) Activity-dependent modulation of nerve terminal excitation in a mammalian peptidergic system. Trends Neurosci 14:28-30.

Brodin L, Grillner S, Rovainen CM (1985) N-Methyl-D-aspartate (NMDA), kainate and quisqualate receptors and the generation of fictive locomotion in the lamprey spinal cord. Brain Res 325:302-306.

Buchanan JT (1982) Identification of interneurons with contralateral caudal axons in the lamprey spinal cord: synaptic interactions and morphology. J Neurophysiol 47:961-975.

Buchanan JT (1999) Commissural interneurons in rhythm generation and intersegmental coupling in the lamprey spinal cord. J Neurophysiol 81:2037-2045.

Buchanan JT, Cohen AH (1982) Activities of identified interneurons, motoneurons and muscle fibres during fictive swimming in the lamprey and effects of reticulospinal and dorsal cell stimulation. J Neurophysiol 47:948-960.

Buchanan JT, Grillner S (1987) Newly identified "glutamate interneurons" and their role in locomotion in the lamprey spinal cord. Science 236:312-314

Buchanan JT, Grillner S (1988) A new class of small inhibitory interneurones in the lamprey spinal cord. Brain Res 438:404-407.

Buchanan JT, Kasicki S (1995) Activities of spinal neurons during brain stem-dependent fictive swimming in lamprey. J Neurophysiol 73:80-87.

Buchanan JT, Kasicki S (1999) Segmental distribution of common synaptic inputs to spinal motoneurons during fictive swimming $\mathrm{n}$ the lamprey. J Neurophysiol 82:1156-1163.

Buchanan JT, Grillner S, Cullheim S, Risling M (1989) Identification of excitatory interneurons contributing to generation of locomotion in lamprey: structure, pharmacology, and function. J Neurophysiol 62:59-69.

Cash S, Yuste R (1999) Linear summation of excitatory inputs by CA1 pyramidal neurons. Neuron 22:383-394.

Cook EP, Johnston D (1999) Voltage-dependent properties of dendrites that eliminate location-dependent variability of synaptic input. J Neurophysiol 81:535-543.

Dale N, Kandel ER (1990) Facilitatory and inhibitory transmitters modulate spontaneous transmitter release at cultured Aplysia sensorimotor synapses. J Physiol (Lond) 421:203-222.

Dunlap K, Luebke JI, Turner TJ (1995) Exocytotic Ca2+ channels in mammalian central neurons. Trends Neurosci 18:89-98.

Fagerstedt P, Wallen P (1992) Morphology and postsynaptic effects of small crossing interneurons in the lamprey spinal cord. Eur J Neurosci [Suppl] 5:136.

Fagerstedt P, Wallén P (1993) Identification of local crossing interneurons in the lamprey spinal cord, using intracellular recording of retrogradely pre-labelled cells visualized with fluorescence microscopy. Eur J Neurosci [Suppl] 6:276.

Fedirchuk B, Wenner P, Whelan PJ, Ho S, Tabak J, O’Donovan MJ (1999) Spontaneous network activity transiently depresses synaptic transmission in the embryonic chick spinal cord. J Neurosci 19:2102-2112.

Forsythe ID, Clements JD (1990) Presynaptic glutamate receptors depress excitatory monosynaptic transmission between moues hippocampal neurones. J Physiol (Lond) 429:1-16.

Forsythe ID, Tsujimoto T, Barnes-Davis M, Cuttle M, Takahashi T (1998) Inactivation of presynaptic calcium current contributes to synaptic depression at a fast central synapse. Neuron 20:797-807.

Gad H, Low P, Zotova E, Brodin L, Shupliakov O (1998) Dissociation between $\mathrm{Ca}^{2+}$-triggered synaptic vesicle exocytosis and clathrinmediated endocytosis at a central synapse. Neuron 21:607-616.

Getting PA (1989) Emerging principles governing the operation of neural networks. Annu Rev Neurosci 12:185-204.

Grillner S, Ekeberg Ö, El Manira A, Lansner A, Parker D, Tegner J, Wallén P (1998) Intrinsic function of a neuronal network-a vertebrate central pattern generator. Brain Res Rev 26:184-197.

Hellgren J, Grillner S, Lansner A (1992) Computer simulation of the segmental neural network generating locomotion in lamprey by using populations of network interneurons. Biol Cybern 68:1-13.

Hjelmstad GO, Isaac JTR, Nicoll RA, Malenka RC (1999) Lack of AMPA receptor desensitisation during basal synaptic transmission in the hippocampal slice. J Neurophysiol 81:3096-3099.

Hsu S-F, Augustine GJ, Jackson MB (1996) Adaptation of Ca2+triggered exocytosis in presynaptic terminals. Neuron 17:501-512.

Jensen K, SkovGaard Jensen M, Lambert JDC (1999) Role of presyn- 
aptic L-type $\mathrm{Ca}^{2+}$ channels in GABAergic synaptic transmission in cultured hippocampal neurons. J Neurophysiol 81:1225-1230.

Johnston D, Magee JC, Colbert CM, Christie BR (1996) Active properties of neuronal dendrites. Annu Rev Neurosci 19:165-186.

Jones MV, Westbrook GL (1996) The impact of receptor desensitisation on fast synaptic transmission. Trends Neurosci 19:96-101.

Kamiya H, Zucker RS (1994) Residual Ca2+ and short-term synaptic plasticity. Nature 371:603-606.

Katz B (1966) Nerve, muscle and synapse. McGraw Hill, New York.

Klein M (1995) Modulation of ion currents and regulation of transmitter release in short-term synaptic plasticity: the rise and fall of the action potential. Invert Neurosci 1:15-24.

Klein M, Shapiro E, Kandel E (1980) Synaptic plasticity and the modulation of the calcium current. J Exp Biol 89:117-157.

Klingauf J, Kavalali ET, Tsien RW (1998) Kinetics and regulation of fast endocytosis at hippocampal synapses. Nature 394:581-585.

Krieger P, El Manira A, Grillner S (1996) Activation of pharmacologically distinct metabotropic glutamate receptors depresses reticulospinal-evoked monosynaptic EPSPs in the lamprey spinal cord. J Neurophysiol 76:3834-3841.

Krieger P, Grillner S, El Manira A (1998) Endogenous activation of metabotropic glutamate receptors contributes to burst frequency regulation in the lamprey locomotor network. Eur J Neurosci 10:3333-3342.

Krieger P, Buschges A, El Manira A (1999) Calcium channels involved in synaptic transmission from reticulospinal axons in lamprey. J Neurophysiol 81:1699-1705.

Kusano K, Landau EM (1975) Depression and recovery of transmission at the squid giant synapse. J Physiol (Lond) 245:13-32.

Liley AW, North KAK (1953) An electrical investigation of the effects of repetitive stimulation on mammalian neuromuscular junction. J Neurophysiol 16:509-527.

Lisman JE (1997) Bursts as a unit of neural information: making unreliable synapses reliable. Trends Neurosci 20:38-43.

Llinas R, Grunner JA, Sugimori M, Mcguinness TL, Greengard P (1991) Regulation by synapsin 1 and $\mathrm{Ca}^{2+}$ calmodulin dependent protein kinase 11 of transmitter release in squid giant synapse. J Physiol (Lond) 436:257-282.

Man-Song H, Zoran MJ (1989) A neuromodulator of synaptic transmission acts on the secretory apparatus as well as on ion channels. Nature 341:237-239.

Manor Y, Nadim F, Abbott LF, Marder E (1997) Temporal dynamics of graded synaptic transmission in the lobster stomatogastric system. J Neurosci 17:5610-5621.

Miller RJ (1998) Presynaptic receptors. Annu Rev Pharmacol Toxicol 38:201-227.

Ohta Y, Dubuc R, Grillner S (1991) A new population of neurons with crossed axons in the lamprey spinal cord. Brain Res 564:143-148.

Otis T, Zhang S, Trussell LO (1996) Direct measurement of AMPA receptor desensitisation induced by glutamatergic synaptic transmission. J Neurosci 16:7496-7504.

Parker D (1995) Depression of synaptic connections between identified motor neurons in the locust. J Neurophysiol 74:529-538.

Parker D, Grillner S (1999) Activity-dependent metaplasticity of inhibitory and excitatory synaptic transmission in the lamprey spinal cord locomotor network. J Neurosci 19:1647-1656.
Parker D, Zhang W, Grillner S (1998) Substance P modulates NMDA responses and causes long-term protein synthesis-dependent modulation of the lamprey locomotor network. J Neurosci 18:4800-4813.

Rovainen CM (1967) Physiological and anatomical studies of large neurons of central nervous system of the sea lamprey (Petromyzon marinus). II. Dorsal cells and giant interneurons. J Neurophysiol 30:1024-1042.

Rovainen CM (1983) Identified neurons in the lamprey spinal cord and their roles in fictive swimming. In: Neural origin of rhythmic movements (Roberts A, Roberts BL, eds), pp 305-330. Cambridge: Cambridge UP.

Rovainen CM (1986) The contributions of multisegmental interneurons to the longitudinal co-ordination of fictive swimming in the lamprey. In: Neurobiology of vertebrate locomotion (Grillner S, Stein PSG, Forssberg H, Stuart D, Herman R, eds). pp 321-333. London: Macmillan.

Ryan TA (1999) Inhibitors of myosin light chain kinase block synaptic vesicle pool mobilisation during action potential firing. J Neurosci 19:1317-1323.

Senn W, Wyler K, Streit J, Larkum M, Luscher H-R, Mey H, Muller L, Stainhauser D, Vogt K, Wannier T (1996) Dynamics of a random neural network with synaptic depression. Neural Networks 9:575-588.

Shupliakov O, Pieribone VA, Gad H, Brodin L (1995) Synaptic vesicle depletion in reticulospinal axons is reduced by 5-hydroxytryptamine: direct evidence for presynaptic modulation of glutamatergic transmission. Eur J Neurosci 7:1111-1116.

Smith C (1999) A persistent activity-dependent facilitation in chromaffin cells is caused by $\mathrm{Ca}^{2+}$ activation of protein kinase $\mathrm{C} \mathrm{J}$ Neurosci 19:589-598.

Staley KJ, Longacher M, Bain JS, Yee A (1998) Presynaptic modulation of CA3 network activity. Nat Neurosci 1:201-209.

Stevens CF, Wesseling JF (1998) Activity-dependent modulation of the rate at which synaptic vesicles become available to undergo exocytosis. Neuron 21:415-424.

Thomas P, Lee AK, Wong GJ, Almers W (1994) A triggered mechanism retrieves membrane in seconds after $\mathrm{Ca}^{2+}$-stimulated exocytosis in single pituitary cells. J Cell Biol 124:667-675.

Trussell LO, Zhang S, Raman IM (1993) Desensitization of AMPA receptors upon multiquantal neurotransmitter release. Neuron 10:1185-1196.

Varela JA, Sen K, Gibson J, Frost J, Abbott LF, Nelson SB (1997) A quantitative description of short-term plasticity at excitatory synapses in layer 2/3 of rat primary visual cortex. J Neurosci 17:7926-7940.

von Gersdorff H, Matthews G (1994) Inhibition of endocytosis by elevated internal calcium in a synaptic terminal. Nature 370:652-655.

Vyklicky L, Patneau DK, Mayer ML (1991) Modulation of excitatory synaptic transmission by drugs that reduce desensitisation at AMPA/KA receptors. Neuron 7:971-984.

Wallen P, Williams T (1984) Fictive locomotion in the lamprey spinal cord in vitro compared with swimming in the intact and spinal animal. J Physiol (Lond) 347:225-239.

Wu L-G, Betz WJ (1996) Nerve activity but not intracellular calcium determines the time course of endocytosis at the frog neuromuscular junction. Neuron 17:769-779.

Zucker RS (1989) Short-term synaptic plasticity. Annu Rev Neurosci $12: 13-31$ 